\title{
POSSÍVEIS INTERSECÇÕES ENTRE CRIMINOLOGIA CULTURAL E ARTES VISUAIS
}

\author{
Herson Alex Santos ${ }^{1}$ \\ Renato Duro Dias ${ }^{2}$
}

\section{RESUMO}

Esta investigação problematiza as relações entre violência e poder, tendo como objetos de análise as obras da artista visual Regina Silveira na exposição Crash. Pretende-se, assim, discutir a banalização da violência e suas construções históricas e culturais nos espaços e discursos em que as situações de exclusão social atuam. Para tal, utilizar-se-á de conceitos da criminologia cultural, arte politicamente engajada, bem como se fará uso de estudos que procurem dialogar o campo do direito e da arte visuais. Neste sentido, este estudo de abordagem qualitativa com análise de imagens e de objetos visuais, pretende reflexionar sobre questões sociais emergentes.

Palavras-chave: criminologia cultural, artes visuais, violência, imagens.

\section{POSSIBLE INTERSECTIONS BETWEEN CULTURAL CRIMINOLOGY AND VISUAL ARTS}

\begin{abstract}
This research problematizes the relations between violence and power, having as objects of analysis the works of the visual artist Regina Silveira in the Crash's exhibition. The aim is discuss the banalization of violence and its historical and cultural constructions in the spaces and discourses in which situations of social exclusion. To this end, concepts of cultural criminology, politically engaged art will be used, as well as studies that seek to dialogue in the field of visual law and art. This study of qualitative approach with analysis of images and visual objects, intends to reflect on emerging social issues.
\end{abstract}

Keywords: cultural criminology, visual arts, violence, images.

\section{INTRODUÇÃO}

\footnotetext{
${ }^{1}$ Bacharel em Direito; aluno de Graduação em Psicologia e; aluno de Pós-Graduação, Mestrado em Direito e Justiça Social, todos pela Universidade Federal do Rio Grande - FURG.

2 Pró-Reitor de Graduação da Universidade Federal do Rio Grande (FURG), estando vinculado a esta universidade como Professor da Faculdade de Direito e do Programa de Pós-Graduação em Direito (Mestrado em Direito e Justiça Social). Atua como Coordenador do Centro de Referência em Direitos Humanos CRDH/FURG. É Doutor em Educação com período de doutoramento sanduíche na Universidade de Lisboa, Portugal. Foi Coordenador eleito dos Cursos de Graduação em Direito (FURG) por três mandatos. Professor Visitante no Instituto de Educação da Universidade de Lisboa, Portugal. Pesquisador do GTJUS - Grupo Transdisciplinar em Pesquisa Jurídica para a Sustentabilidade. Codiretor da Revista Pedagogía Universitária y Didáctica del Derecho, Facultad de Derecho, Universidad de Chile. Editor Chefe da Revista de Gênero, Sexualidade e Direito - CONPEDI. Advogado. Diretor de Comunicação da ABEDi. Associado ao CONPEDI, ABEDi e a REED. Possui publicações de livros, organizador, capítulos de livros e artigos científicos, em revistas nacionais e internacionais indexadas.Tem interesse nas áreas de educação superior, ensino jurídico e direitos humanos, especialmente nas temáticas de gênero e sexualidades.
} 
Com esta investigação se problematiza as relações entre violência e poder, tendo como objetos de análise as obras da artista visual Regina Silveira na exposição Crash (SILVEIRA, 2015). Pretende-se, assim, discutir a banalização da violência e suas construções históricas e culturais (FOUCAULT, 2009, 2014) nos espaços e discursos em que as situações de exclusão social atuam.

Para tal, utilizar-se-á de conceitos da criminologia cultural (FERRELL, 1995, CARVALHO, 2009 e ZAFFARONI, 2015a), arte politicamente engajada (BOURRIAUD, 2009; GUATARRI, 1996), bem como se fará uso de estudos recentes que procuram dialogar o campo do direito e da arte (DIAS, 2015, 2016), das imagens (PANOFSKY, 1986, 2011) e da política.

Embora recentes nas ciências sociais, entende-se que os estudos imagéticos produzem potentes reflexões sobre os estudos culturais, já que manejam as análises para além do texto escrito, possibilitando e ampliando as interpretações. No campo do direito, especialmente na criminologia cultural, estas pesquisas têm contribuindo para visualizar os aspectos culturais e, ao mesmo tempo, encaminhar importantes debates levantados pelos meios de comunicação (mídia), o cinema, a música e as artes visuais.

Por outro lado, quando se discute os sistemas punitivos e as relações societárias impregnadas de violência, se faz necessário proceder a outros instrumentos investigativos para além dos parâmetros convencionais do direito. Neste sentido, este estudo de abordagem qualitativa com análise de imagens e de objetos visuais, pretende, primeiramente, reflexionar sobre questões sociais emergentes.

Importa frisar, que este artigo se trata de um recorte de uma pesquisa mais abrangente em que se pretenderá verificar como presos em regime fechado, que cometeram crimes "a mão armada", encarcerados em uma casa de detenção no Rio Grande do Sul, e policiais militares, deste mesmo estado, percebem e descrevem estas mesmas imagens (SILVEIRA, 2015), que ora serão descritas e analisadas.

Vale dizer, neste estudo apresentam-se imagens da artista visual, discute-se sob o ponto de vista iconográfico/iconológico e da criminologia cultural. Para em momento futuro, problematizar estes elementos, contextualizando-os às percepções de agentes (presos e 
policiais) em espaços semelhantes de exclusão social e cultural, mas que por contingências se apresentam como opostos no campo criminal (ZAFFARONI, 2015a).

Assim, este estudo procurará articular a arte e o direito pretendendo responder algumas questões de pesquisa, dando ênfase a pensar em que medida os discursos presentes no campo das artes visuais podem contribuir para discutir as categorias violência e poder no contexto da produção da criminologia cultural e no direito.

Para tal, o percurso expositivo contará com uma breve introdução e um situar no contexto contemporâneo da violência e dos sistemas punitivo e de vigilância. A seguir, selecionar-se-ão de Crash (SILVEIRA, 2015), quatro (04) obras: Encuentro (1991), Duelo (2013), Insidelout (Gun) (1996) e Crash (2014), a fim de estabelecer diálogo sobre o campo da criminologia cultural e, ao final, apontar algumas considerações, refletindo, sobretudo, estas intersecções possíveis entre os campos da arte e do direito.

\section{Violências, relações de poder e sistema punitivo-carcerário brasileiro}

Castigo, disciplina e punição do corpo são categorias exploradas por Foucault em algumas de suas obras, especialmente Vigiar e punir: nascimento da prisão (2014). Neste texto, com riqueza de detalhes, a narrativa foucaultiana explora os regimes disciplinários e de docilização dos corpos a partir do lócus do sistema prisional, espaço no qual o autor didaticamente estabelece e demarca: suplício, punição, disciplina e prisão.

Segundo Michel Foucault (2009), o significado da prisão nasce da percepção de que vigiar é mais eficiente do que punir, o que tornaria o sistema prisional um estabelecimento de observação por excelência. Este sistema de vigilância, no entanto, não se adequa totalmente à realidade dos presídios brasileiros: sistema prisional fraturado e em esgotamento, já que mais se aproxima a um depósito de criminosos. A prisão serve para produzir novos criminosos ou afundá-los ainda mais na criminalidade (FOUCAULT, 2009, p. 131), deste modo alimentando a demanda do Estado por este tipo de objeto: criminalidade/criminoso, que é, em última análise, de importância impar para qualquer discurso político por repercuta direta e indiretamente na economia (FOUCAULT, 2009, p. 132). 
Dizem que a prisão fabrica delinquentes; é verdade que ela leva de novo, quase fatalmente, diante dos tribunais aqueles que lhe foram confiados. Mas ela os fabrica no outro sentido de que ela introduziu no jogo da lei e da infração, do juiz e do infrator, do condenado e do carrasco, a realidade incorpórea da delinquência que os liga uns aos outros e, há um século e meio, os pega todos juntos na mesma armadilha. (FOUCAULT, 2014, p. 248).

Sob este viés, o grupo mais propenso a ser utilizado neste processo é o dos pobres ao ser o que mais sofre com a delinquência e é desse mesmo grupo que se recruta a delinquência (FOUCAULT, 2009, p. 133). Esta característica evidenciada por Foucault (2008 e 2014) tende a gerar um sentimento de anomia generalizada que pode ser muito útil no plano político.

A intensificação da realidade, caótica ${ }^{3}$, dos presídios brasileiros nos últimos meses com as rebeliões ${ }^{4}$ nas regiões norte e nordeste do país, longe de descortinar um problema que já é conhecido de longa data, reforçou inúmeros debates sobre a crise penitenciária. Tal crise é um problema sério a ser discutido, porém antes disso ela remete à sua origem genealógica e que deve ser abordada antes com a mesma seriedade: trata-se da questão criminal, em específico a criminalização.

A efemeridade da relevância ou os "quinze minutos" de destaque que a crise penitenciária ganhou na grande mídia deu voz, de uma maneira negativa, a um grupo de pessoas que não é ouvido. Esta voz ou discurso negativo, manipulado de forma sensacionalista pela grande mídia, fomenta uma torrente de outras manifestações vulgares, por parte de empresários morais ${ }^{5}$, no sentido de promoção de campanhas higienistas que flertam

\footnotetext{
${ }^{3}$ Nosso sistema punitivo, forjado sob o signo das matrizes do patrimonialismo, da escravidão e da exclusão, consagrou um padrão organizacional e estrutural de estabelecimentos penais que são o retrato da violação de direitos das pessoas privadas de liberdade (ZAFFARONI, 2006). Em 2014 segundo o senso INFOPEN, constatou-se que $74 \%$ dos presos brasileiros eram jovens entre 18 e 34 anos e esses números são ainda mais alarmantes para jovens entre 18 e 24 anos que, na época, correspondiam a 11,16\% da população e desse total $30,12 \%$ estavam presos - quase um terço (infopen2014). Do total de presos a porcentagem de negros era de $61,67 \%$. Com relação à instrução: apenas $9,5 \%$ da população carcerária havia concluído o ensino médio, sendo que a média nacional no mesmo período era cerca de $32 \%$. Esse grande contingente de jovens pobres, com pouca ou nenhuma instrução, de regiões periféricas e, na sua maioria, negros, abre espaço para uma grande margem de discussões. Porém, aqui pretendemos procurar a origem das vidas nuas que compõem o espaço penitenciário. (INFOPEN, 2014).

4 "Mortes em presídios do país em 2017 já superam o massacre do Carandiru". Reportagem de 16/01/2017. Disponível em: http://g1.globo.com/bom-dia-brasil/noticia/2017/01/mortes-em-presidios-do-pais-em-2017-jasuperam-o-massacre-do-carandiru.html <acessado em 03/04/2017>.

${ }^{5} \mathrm{O}$ conceito de empresário moral foi enunciado sobre observações relativas a outras sociedades, mas na nossa pode ser tanto um comunicador social, após uma audiência, um político em busca de admiradores ou um grupo religioso à procura de notoriedade, quando um chefe de policia à acata de poder ou uma organização que reivindica os direitos da minorias etc. Em qualquer um dos casos, a empresa moral acaba desembocando um fenômeno comunicativo: não importa o que seja feito, mas sim como é comunicado. A reivindicação contra a impunidade dos homicidas, dos estupradores, dos ladrões e dos meninos de rua, dos usuários de drogas etc., não
} 
com as práticas de depuração racial aplicadas na Alemanha nazista (ZAFFARONI, 2015a, p. 77), ou então propostas mais amenas que vão desde a construção de mais presídios, efetivação das audiências de custódia até a intervenção militar por parte das forças armadas, dentre outras tantas que em sua maioria se preocupam somente com o sintoma - a superlotação.

Porém, é inegável que, em meio aos discursos mais variados, os holofotes se voltaram, em demasia, para pessoas que são renegadas ao esquecimento. Estamos falando de uma população que, em 2014, já correspondia a mais de 620.000 (seiscentos e vinte mil) presos sem contar com os presos em delegacias, cerca de 300 presos por 100.000 habitantes, sendo que a média mundial é de 144 presos por 100.000 habitantes segundo o INFOPEN ${ }^{6}$ e com base em dados do ICPS (International Center for Prision Studies). Garantindo ao país, deste modo, a posição de quarta nação com maior número absoluto de presos no mundo. Um número vertiginoso de pessoas que muitas vezes vivem e morrem em um estado, paradoxalmente, paralelo à legalidade.

Este paradoxo se dá pelo fato de o Estado os ter colocado em tal situação paralela a partir de um processo de criminalização que se inicia muito antes do ato delituoso, mas sim nos estereótipos procurados pela criminalização secundária, que é, de forma bastante sintética, a ostensividade policial, na busca por clientes ideais para o sistema penal (ZAFFARONI, 2015b, p. 40), e que a partir da lei, criada no processo de criminalização primário, usa dos estereótipos, do tipo: classe social, cor de pele, sexo, idade, etc. (ZAFFARONI, 2015b, p. 40), para dar uma identidade à figura do criminoso que pouco ou nada mudou desde a época de Enrico Ferri (1995) ${ }^{7}$.

Essa legião de presos que cometeram diversos crimes, além dos que aguardam julgamento ${ }^{8}$ - e que, dentro deste subgrupo, por acaso nada cometeram, mas lá estão -, no contexto discursivo embrutecido social veem a serem considerados "vidas nuas" (AGAMBEN, 2002, p. 13), no espaço artificial criado pelo poder punitivo ao excluir da

se resolve nunca com a respectiva punição de fato, mas sim com urgentes medidas punitivas que atenuem as reclamações na comunicação ou permitem que o tempo lhes dê a centralidade comunicativa. (ZAFFARONI, 2006, p. 45).

${ }^{6}$ Levantamento Nacional de Informações Penitenciárias - Dezembro de 2014

${ }^{7}$ Enrico Ferri foi um criminologista e político socialista italiano. É considerado um dos fundadores da Escola Italiana de Criminologia Positivista, que acreditava no criminoso atávico e para entender tal suposição estudava o fenótipo universal dos reclusos, o que acabou por descortinar as características de quem era perseguido pelo Estado no processo de criminalização.

${ }^{8}$ Presos provisórios que eram em 2014 mais de 40\% do total segundo o INFOPEN. 
proteção jurídica as formas de vida que não se submeteram a ordem Estatal. O poder punitivo, torna desse modo, o aprisionado no homo sacer da pós-modernidade, que como explica Giorgio Agamben (AGAMBEN, 2002, p. 30), desde as penas de banimento romanas, é forçado a viver em um terreno vago, submetido a um estado de exceção, tornando-se assim uma vida que não merece ser vivida e por isso uma "vida matável" com pouca ou nenhuma consequência, AGAMBEN (AGAMBEN, 2002, p. 166).

Essas vidas nuas não são relevantes, ainda que diariamente, eliminadas dentro da caótica esfera prisional nacional. No entanto, quando esse conta-gotas mortífero se transforma em uma torrente com mais de cem mortos em um espaço curtíssimo de tempo, a mídia que em sua busca desmedida por índices de audiência em conjunto a uma mórbida tendência de consumo de notícias, acaba por alçar a questão penitenciária brasileira à mídia mundial quase que instantaneamente por consequência da mundialização.

Neste sentido atua a "pedagogia da mídia", que abastece o cotidiano com representações dos sujeitos, produzindo-os discursivamente.

Fundamentada no conceito de "dispositivo da sexualidade" de Foucault (1990a, p. 100), descrevo o dispositivo pedagógico da mídia como um aparato discursivo (já que nele se produzem saberes, discursos) e ao mesmo tempo não discursivo (uma vez que está em jogo nesse aparato uma complexa trama de práticas, de produzir, veicular e consumir TV, rádio, revistas, jornais, numa determinada sociedade e num certo cenário social e político), a partir do qual haveria uma incitação ao discurso sobre "si mesmo", à revelação permanente de si; tais práticas vêm acompanhadas de uma produção e veiculação de saberes sobre os próprios sujeitos e seus modos confessados e aprendidos de ser e estar na cultura em que vivem. (FISCHER, 2002, p. 154).

Em conjunto com a vulnerabilidade, está a grande mídia que ao mesmo tempo fomenta e dissemina estereótipos e um sentimento irrefletido de estado de barbárie muito maior do que a realidade apresenta (ZAFFARONI, 2015a, p. 10), fazendo uso de mensagens sensacionalistas muitas vezes vinculadas a um bombardeio massivo de imagens extremas de violência, e conjuntamente a um discurso muitas vezes moralizante e por demais simplistas, isso quando os têm e não faz uso somente de imagens recortadas sem muito ou nada de contexto (ZAFFARONI, 2015a, p. 194).

Neste contexto midiático, com tal processo de criminalização, tem-se também o processo de policialização que vem da interiorização da mensagem que a grande mídia passa 
- de constante estado de guerra contra o inimigo social (bandido) -, em batalhas intermináveis do bem contra o mal, diante dessa internalização da mensagem midiática, ao incorpora-se à polícia, o ambiente tende a fazer seu papel no processo de criação da identidade policial estereotipada.

Assim, do mesmo modo como muitas vezes ocorre nos presídios que acabam se transformam em faculdade do crime, os quartéis são fabricas (de)formadoras do pensamento policial. Uma vez dentro da corporação o agente tende a gradualmente perder sua identidade e em contrapartida assume uma identidade policial (ZAFFARONI, 2015b, p. 139).

A contemporaneidade, em que o mundo olha para o Brasil, faz com que a pauta da criminalidade seja aqui discutida de forma mais intensa em diferentes locais como a própria grande mídia, as mídias alternativas ou redes sociais no ciberespaço, seja nos campos do direito, da criminologia cultural e das artes visuais. É o que se percebe em CRASH, de Regina Silveira (2015), exposição realizada no Museu Oscar Niemeyer, Curitiba.

Para Ferrell (1995, p. 36-37)

A criminologia cultural oferece, assim, aos criminologistas a oportunidade de
aprimorar suas próprias perspectivas sobre o crime com insights de outros campos,
ao mesmo tempo em que fornece aos seus colegas estudos culturais, sociologia da
cultura, estudos de mídia e outras perspectivas inestimáveis Criminalidade,
criminalização e sua relação com processos culturais e políticos. Dobrar ou quebrar
os limites da criminologia para construir uma criminologia cultural, nesse sentido,
menospreza a criminologia contemporânea do que a expande e a anima. A
criminologia cultural amplia o domínio da criminologia para incluir mundos
convencionalmente considerados exteriores a ela: arte de galeria, música popular,
operações de mídia e textos, estilo. Da mesma forma, introduz a criminologia nos
debates contemporâneos sobre esses mundos, e define perspectivas criminológicas
como essenciais para eles. As relações específicas entre cultura e criminalidade e a
relação mais ampla entre a criminologia e a vida social e cultural contemporânea
estão ambas iluminadas pela criminologia cultural. ${ }^{9}$

${ }^{9}$ Tradução livre de: "Cultural criminology thus provides criminologists the opportunity to enhance their own perspectives on crime with insights from other fields, while at the same time providing for their colleagues in cultural studies, the sociology of culture, media studies, and elsewhere invaluable perspectives on crime, criminalization, and their relationship to cultural and political processes. Bending or breaking the boundaries of criminology in order to construct a cultural criminology in this sense undermines contemporary criminology less than it expands and enlivens it. Cultural criminology widens criminology's domain to include worlds conventionally considered exterior to it: gallery art, popular music, media operations and texts, style. In the same way, it introduces criminology into contemporary debates over these worlds, and defines criminological perspectives as essential to them. The specific relationships between culture and crime, and the broader relationship between criminology and contemporary social and cultural life, are both illuminated within cultural criminology." 
De acordo com Carvalho (2009, p. 326)

A criminologia cultural configura-se como criminologia estética de análise de ícones e símbolos mercantilizados pelos meios formais e informais de comunicação. Por este motivo representações televisivas, cinematográficas, artes plásticas, teatro, expressões e estilo musicais, campanhas publicitárias, websites, vídeo games, moda urbana e práticas desportivas e de entretenimento, sejam transgressivas ou conformistas, apresentam-se potenciais objetos de análise que fala do sujeito contemporâneo.

Assim as obras da artista visual Regina Silveira potencializam esta mirada sobre os estudos culturais, no campo da violência, entrelaçado arte, criminologia cultura e direito.

\section{Artes visuais, imagens, criminologia cultural e direito em Crash (2015)}

Os usos das obras de artes, fotografias, filmes e peças publicitárias como documentos de análise estão consolidados nos campos das artes visuais, da sociologia e da antropologia. Dentro do direito, as pesquisas que envolvem estas metodologias e abordagens visuais ganham impactam e reflexão a partir dos estudos culturais, especialmente na criminologia e nas temáticas de gênero e das sexualidades.

No próprio CONPEDI, Conselho Nacional de Pesquisa e Pós-graduação em Direito, a criação de um Grupo de Trabalho (GT) específico sobre Direito, Arte e Literatura irá se consolidar em 2009, no Encontro Nacioanl em Maringá, PR, quando por primeira vez a palavra "arte" é colocada no título do GT, então denominado "Direito, Arte, Literatura e Interdisciplinaridade" ${ }^{10}$. Embora seja importante salientar que, em edições anteriores, trabalhos científicos eram publicados e discutidos em outros espaços do mesmo CONPEDI.

$\mathrm{Na}$ medida em que estas investigações vão sendo produzidas, mais espaço para a arte e suas linguagens se consolida como dispositivo analítico, carregado de significações. No caso Crash de Silveira (2015), seus objetos, silhuetas, jogos de luzes e sombras constituem uma experiência visual capaz de deslocar os sentidos para a arte contemporânea, sem, no entanto se desgarrar da singularidade do sujeito atravessado por espaços-tempos em que

\footnotetext{
${ }^{10}$ Ver Anais do XVIII Encontro Nacional do CONPEDI, Maringá, PR. Realizado em 03 e 04 de junho de 2009, em Maringá, Paraná. https://s3.amazonaws.com/conpedi2/anteriores/XVIII+Encontro+Nacional+-+CESUMARMaring\%C3\%A1+(02\%2C+03+e+04+de+julho+de+2009).pdf <acesso 07.05.2015>
} 
representações e realidade se enredam.

As silhuetas parecem simples, quando pensamos apenas em contornos preenchidos e escuros - mas elas são na verdade muito ambíguas e se prestam a diversas fantasmagorias. As silhuetas sombreadas sempre permitiram jogos de imaginação extraordinários, secularmente, em diversas artes. As silhuetas que representam sombras conservam os dados de ausência que as sombras têm no real, onde elas não são imagens, mas signos ligados a uma origem, de que são vestígios e indícios, com implicações de tempo e memória. Para mim sempre foi do maior interesse a relação - mental e temporal - que as sombras manchem com seus referentes, presentes ou ausentes. Enfim, um vasto campo para operações poéticas, que quase sempre concebi em termos de substituições e distorções. (HAAG, 2010, p. 12)

De Crash (2015), para este estudo, escolheu-se quatro (04) obras: Encuentro (1991), Duelo (2013), Insidelout (Gun) (1996) e Crash (2014).

\section{Encuentro}

É o que acontece em Encuntro (SILVEIRA, 1991). Uma das primeiras obras de grandes dimensões, um vinil adesivo colado na parede, em que a artista se utiliza do efeito da perspectiva entre imagem e sombra, para produzir reflexão sobre estas "fantasmagorias". Numa obra que mistura a foto dos todo-poderosos do G- $7^{11}$, entre eles a ex-primeira-ministra britânica Margaret Thatcher e suas sombras: um parafuso, uma tesoura, um serrote, um estilingue, um revólver (arma), um saca-rolha e uma lâmina de corte.

Imagem 1 - Encuentro (SILVEIRA, 1991).

${ }^{11}$ O Grupo dos Sete é um grupo internacional composto por: Estados Unidos, Alemanha, Canadá, França, Itália, Japão e Reino Unido 


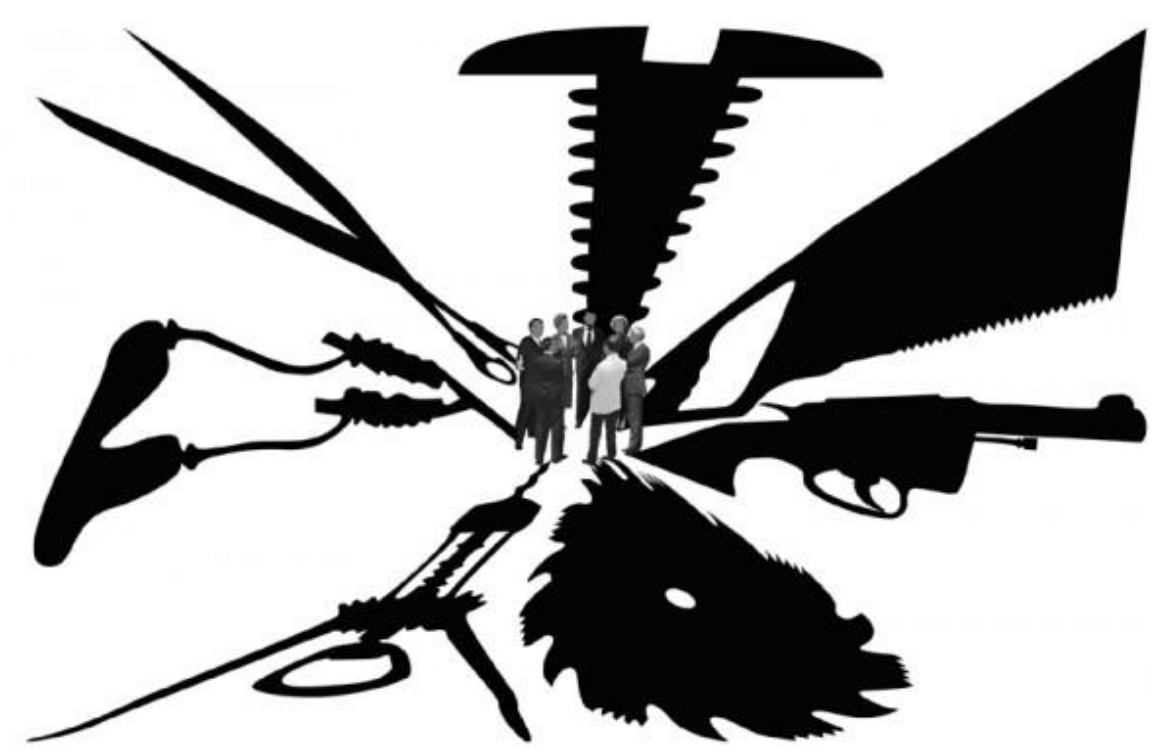

Fonte: Silveira (2015).

Encuentro (SILVEIRA, 1991), que também foi originalmente exposto como outdoor espalhado na cidade de São Paulo, SP, problematiza, sobretudo, as relações de poder (de) marcadas em um processo de globalização, para além da violência simbólica objetual, pode nos sugerir inúmeras significações dentre as que se inserem na exploração do capital (mercado), na medida em que apresenta um parafuso, ícone da representação industrial; discute a questão ambiental, já que apresenta o serrote e a lâmina de corte, como símbolos dos cortes de árvores, desmatamento e devastação florestal; a tesoura, que é utilizada como instrumento cortante, e vinculada a imagem da ex-Ministra britânica, associa-se às políticas neo-liberais e de corte de gastos públicos.

Todos estas possíveis significâncias se aproximam do que a própria artista visual diz considerar o sentido da arte pública.

Das intervenções em espaços públicos, as que me parecem mais próximas das funções transformadoras que acredito que a arte deva ter, antes de qualquer coisa, são as que são efêmeras ou que têm um formato transitório, no sentido de provocar seu efeito e logo desaparecer. A arte pública permanente, mesmo a que não se propõe como "monumento", implica outras contingências e negociações - com diferentes graus de dificuldade - que envolvem seu significado e seu uso. De qualquer modo, efêmera ou permanente, a arte pública se situa no espaço da vida. (HAAG, 2010, p.15)

Estes simulacros, propostos por Silveira, oportunizam reverberações em espaciais. 
Simulacros é a denominação abrangente de um conjunto de trabalhos cuja característica comum é a representação de sombras projetadas [...]é uma crítica às imagens perspectivadas e seus pressupostos de realismo, com foco nas extensões paradoxais da Perspectiva, onde a transgressão das normas dá trânsito livre às propriedades deformantes e enfatiza sua artificialidade [...] (SILVEIRA, 1984, p. 02)

\section{Duelo}

Em Duelo, uma obra mais recente, de 2015, Silveira novamente nos interpela a problemática da violência, a partir de uma estrutura objetual composta por acrílico e madeira. Trata-se de dois blocos $(115 \times 140 \times 30 \mathrm{~cm})$ (cada), formado de várias lâminas acrílicas, que se configuram expostas (não despropositadamente) frente a frente, como representação de dois revólveres (armas), uma apontando em direção a outra.

Imagem 1 - Duelo (SILVEIRA, 2013).

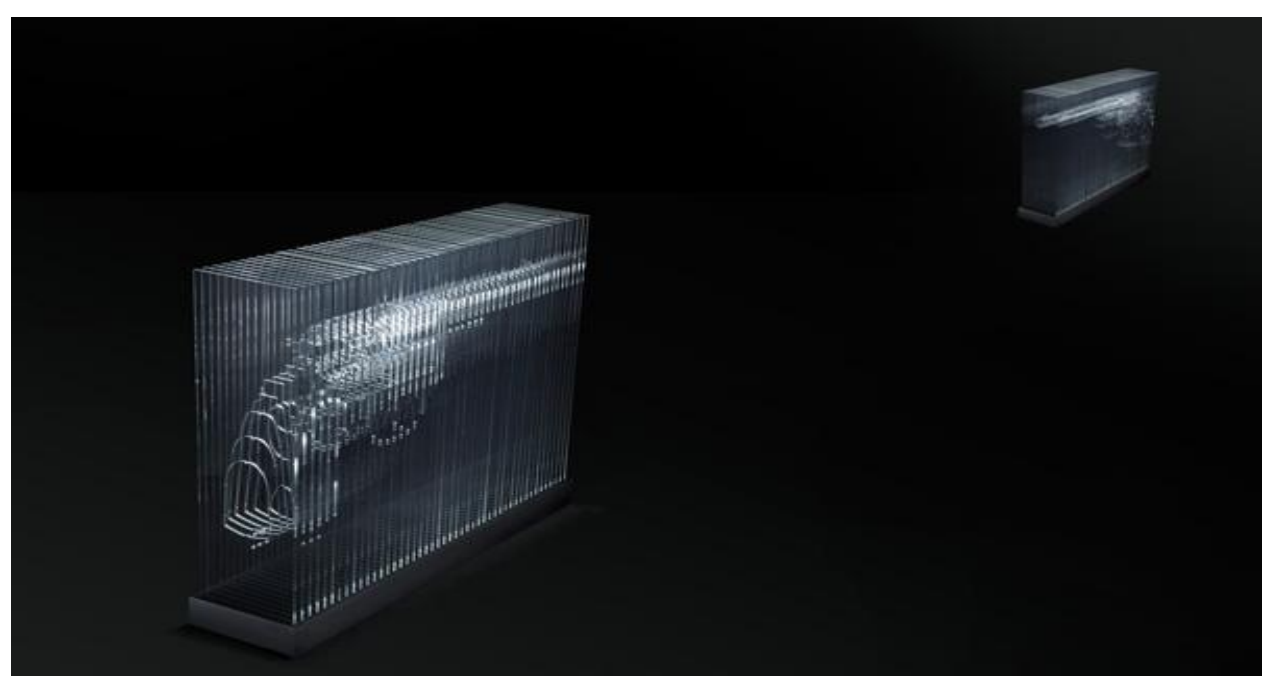

Fonte: Silveira (2015).

Tal obra, posta de modo perfeitamente antagônico potencializa refletir sobre as vidas matáveis. Antes de serem vidas nuas, são vidas sociais e aqui é que se pergunta: quais vidas sociais se transformam e ou são transformadas em vidas nuas no ambiente carcerário-punitivo brasileiro? Para tentar responder a esta questão se faz necessário analisar a identidade característica da vida nua no cotidiano prisional brasileiro, bem como a vida precarizada do policial. Duas faces de uma mesma vida nua.

Ferri (1995), ainda no século XX, dedicou-se a construir um conceito fenotípico de criminoso nato, sabe-se que o apenado possui determinadas características, porém o que se evidenciou mais tarde, ainda no mesmo século, foi que, longe do conceito de criminoso 
atávico, o processo de criminalização seleciona determinados agentes com certas características estereotipadas e pré-determinadas. Na sequência destes estudos, a crminologia ao refletir sobre o processo de criminalização como um todo, acaba por desvelar um paradoxal binarismo, porque na "outra face" do sujeito delinquente (criminoso) estaria, um outro sujeito. E quem faz este papel é a polícia. Uma importante instituição que dá eficácia ao processo primário, a polícia, em especifico, a polícia militarizada ou polícia militar. Contudo, de onde vem este sujeito que compõe o contingente policial? E a resposta apontada por Zaffaroni é, no mínimo, interessante, pois afirma "que os jovens que completam as fileiras policiais advêm do mesmo estrato social dos jovens que são criminalizados" (ZAFFARONI, 2015b, p. 134).

Em determinada camada social (especialmente vulnerável), uma parte flerta, com processo de criminalização, enquanto outra tende ao que Zaffaroni chama de processo de policialização (ZAFFARONI, 2015b, p. 139). A característica que aproxima essas duas faces antagônicas, numa visão maniqueísta e por demais simplista, é a vulnerabilidade. Palavra central para compreender como se dão estes processos de criminalização e policialização, que em uma visão mais atenta formam uma coesão muito maior do que qualquer possível antagonismo, no sentido de convergirem ambas para a manutenção do modelo vigente de sistema punitivo.

No Brasil, a insuficiente formação do policial militar, a falta de acompanhamento e treinamento para a resolução pacífica de conflitos em um ambiente inóspito, machista e arcaico, em que prevalecem condições precárias de trabalho, baixos salários e constante tensão, promove-se a contrução identitária policial sob uma égide perversa e desumana. Atrela-se a estes fatores a falta de reconhecimento por seus iguais, pois no fim do expediente ou plantão, ao retornar à sua casa, em seu bairro, que geralmente é na região periférica, pobre ou de classe média, o veem com certa desconfiança, diante da imagem estereotipada de corrupção, que é amplamente difundida, criando um senso comum que criminaliza o agente policial. A constatação é alarmante, de ambos os "lados" vidas nuas.

Policiais quando morrem não são considerados mais do que soldados caídos em campanha, pois a morte é uma possibilidade intrínseca a guerra, sendo assim, com base do que se espera de um soldado, esta classe não tem voz. Mas assim como os mortos 
criminalizados falam os mortos policializados também falam, e as palavras são as mesmas: "nós estamos mortos!".

Sendo assim, as rebeliões acima citadas, ajudaram-nos a ouvir as palavras dos mortos (ZAFFARONI, 2015a, p. 11), estas palavras que não podem e não têm como ser interpretadas de modo distinto do seu real significado que é: “nós estamos mortos!", e quanto a isso ninguém pode afirmar o contrário. Mais do que isso, as palavras dos mortos dão voz às vidas nuas que, porém, não podem falar por ainda não estarem mortas. Mas antes deste lamentável acontecimento que, na verdade, parecia inevitável diante das condições do sistema prisional, pode-se ver na obra de Regina Silveira (2015) o eco dessas palavras, já que denunciam a vulnerabilidade que vem antes da criminalidade e se funde a esta de modo a ser quase obvia a sua ligação.

Assim, a obra talvez exteriorize o sentimento/percepção (visão de mundo ${ }^{12}$ ) de quem a produz, ao levar em conta questões de tempo e espaço, por mais que a artista não reconheça questões criminológicas tão a fundo para argumentar de modo "lógico", no sentido acadêmico do termo, ainda assim ela é filha de seu tempo, e em conjunto com uma sensibilidade muito aguçada, característica indelével da inclinação artística, fez com que tal excepcional obra fosse produzida. O duelo evidente na imagem pode ser considerada uma síntese do que se levantou até então. Mostrando as duas faces da mesma moeda. A igualdade em origem e formação de ambos os lados, que estão mecanicamente colocados em lados opostos.

O fato de ambas as esculturas serem do mesmo material, de serem perfeitamente iguais, e estarem em duelo, denuncia muito mais do que a igualdade em humanidade de ambos os seres em um duelo qualquer, pode ser signo de uma igualdade na gênese social, na origem.

\section{Inside/out (Gun)}

Insidelout (Gun) (1996), um objeto com serigrafia sobre acrílico (07 x 10 x 4,5 cm) retoma o efeito "armadilha" de Silveira (2015), capturado a partir das imagéticas sombras distorciadmente refletidas (HAAG, 2010). Na obra, a artista visual contemporânea procura

${ }^{12}$ Ver Panofsky (1986). 
mesclar, além do seu tradicional revólver (arma), uma representação de um bispo (peça do xadrez) e de um soldado-de-chumbo, por meio da técnica da perspectiva e o usso de sombras.

Ao explorar as distorções da perspectiva pode-se perceber o que é possível fazer com as imagens que o espectador tem registrado como a imagem das coisas reais. Essa exploração cria essas aparências enganosas, ambiguidades visuais, metamorfoses e paradoxos, e faz do trabalho de Regina Silveira um forte representante da expressão da arte como idéia dentro da produção nacional. (RODRIGUES, 2008, p. 66)

Imagem 3 - Inside/ out (Gun) (SILVEIRA, 1996).

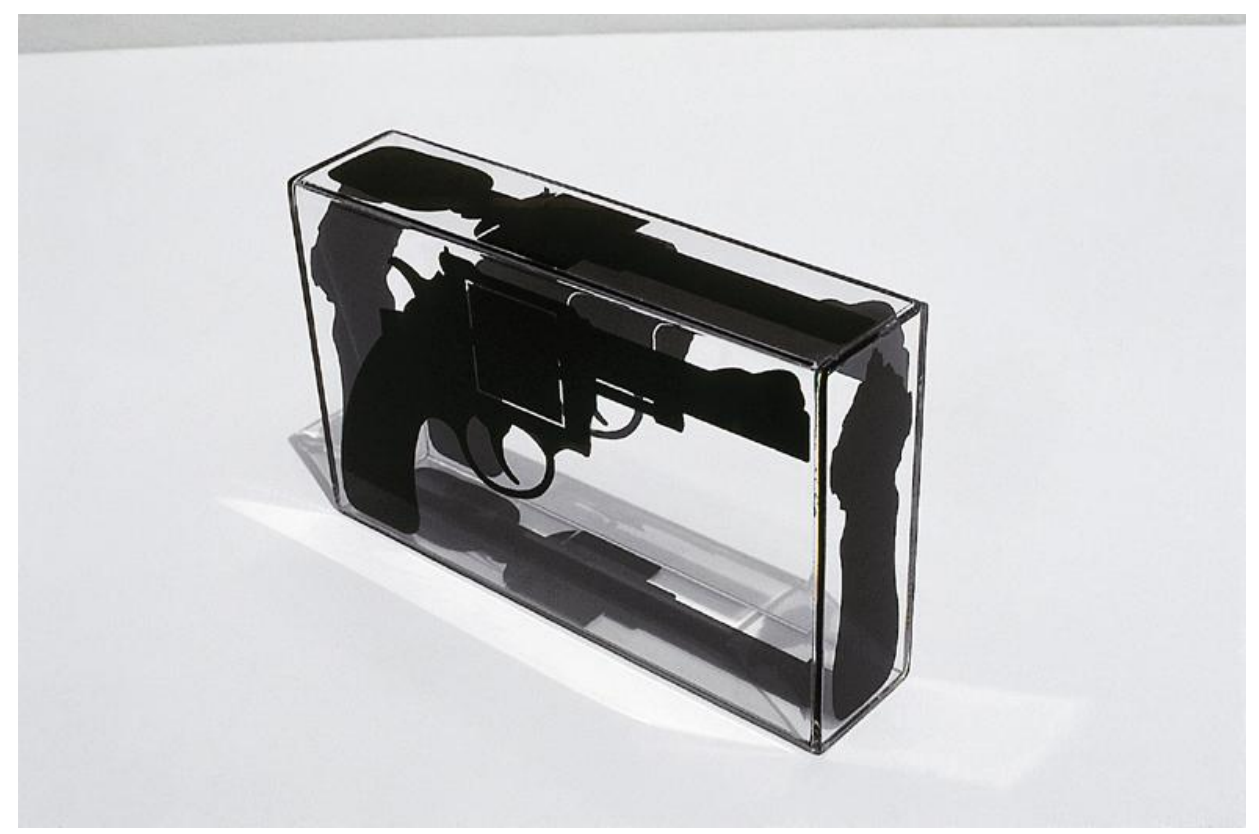

Fonte: Silveira (2015).

A arma, que é referenciada em muitos dos trabalhos expostos na exposição Crash (2015), é aqui a figura central do acrílico. Mais um exemplar das representações de violência do cotidiano, Insidelout (Gun) apresenta uma metalinguagem, na medida em que procura dialogar o poético e o político, diante do objeto característico da violência e sua ligação com figuras de poder instituídas.

Os desenhos de revólveres, tanques e mísseis não refletem só o nosso momento, de violência gritante, mas resume, de acordo com a artista, a história do nosso país. Há obras dos anos 1970, por exemplo, que tem como elemento principal um tanque de guerra. [...]. "É uma balança entre o poético e o político. Falo sobre as circunstâncias de sempre, mas parece adaptado para este momento", contou Regina em entrevista para a Gazeta do Povo, durante a montagem da mostra no MON. (GAZETA DO POVO, 2015) 
Silveira procura dizer que seu trabalho não é assim tão óbvio, mas que produz sob uma proposta que pode estar compreendida como arte politicamente engajada. "Sempre me interessou a educação e a arte como efeito social" (GAZETA DO POVO, 2015)

\section{Crash}

A obra que leva o nome da exposição, contém uma série de objetos. São um conjunto de porcelanas brancas com sobrevidrado perfuradas, quebradas e coladas, bem como peça de madeira com pintura industrial $(50 \times 90 \times 90 \mathrm{~cm})$ que as apoia. Na porcelana estes cortes e rasgos pretos se assemelham (simulam) tiros, o que se apresenta como o reflexo que a obra pretende impactar. $\mathrm{O}$ contraste entre as peças brancas e as perfurações pretas inquieta o espectador, na medida em que o silêncio se faz presente no "cubo branco".

Seria esta uma obra para questionar a violência que transpõe o espaço público e invade a vida provada? Se refere, a autora, à violência doméstica? A artista não revela.

Imagem 4 - Crash (SILVEIRA, 2014).

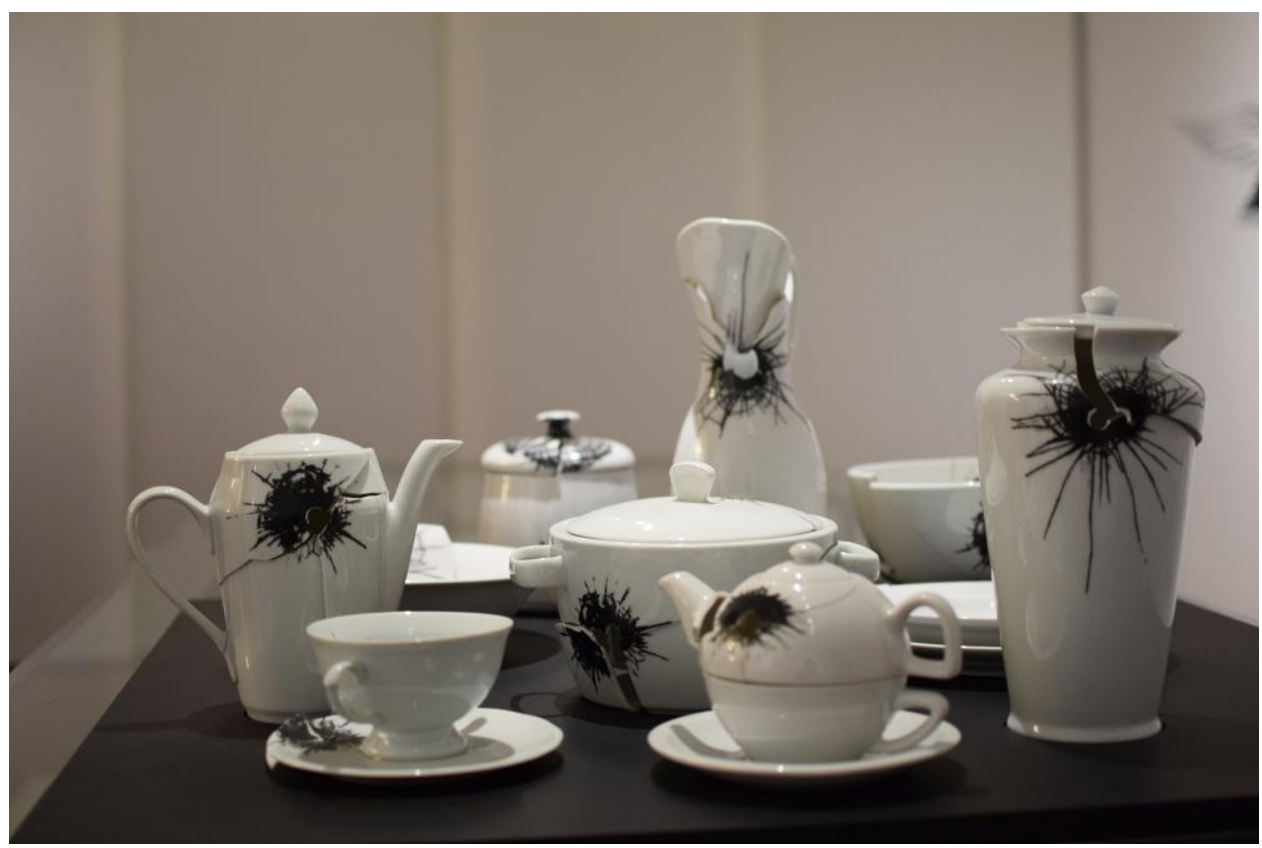

Fonte: SILVEIRA (2015).

As pistas e o impacto visual que a autora produz parecem indicar que sim. As visões assustadoras apontadas nas obras de Silveira (2015) refletem, ainda que num jogo entre 
visibilidades/invisibilidades, as mais variadas formas de violência a que estamos diariamente submetidos. São disparos, armas, tiros, mísseis, tanques. Pode demonstrar a vida que tenta segir em meio a violência que é evidente mas vulgarizada em uma forma não natural de se lidar com ela.

Desde Encuentro (1991) até Crash (2014), a superposição semântica destas imagens nos convida (obriga) a pensar sobre como somos fraturados e atravessados por estas visualidades e em que medida nosso assujeitamento (FOUCAULT, 2009) torna nossos corpos dóceis a reconhecê-las como representações imaginárias de uma realidade cada vez mais próxima.

\section{Considerações finais}

Diante da análise dos conceitos de criminalização e policialização, ligados, aquele a criminalização primária e secundária e este mais aos discursos midiáticos, ambos vinculados genealogicamente a noção de vulnerabilidade, em paralelo com a criminologia midiática, com as análises das obras Encuentro (1991), Crash (2014), Inside/out (gun) (1996) e em especial Duelo (2013), desvela-se o papel das artes visuais como elemento de crítica cultural.

Especialmente em Duelo (2013) enfrenta-se uma oposição binarizante presidiáriospoliciais. De um lado vidas matáveis que só ganham voz para o discurso póstumo: "nós estamos mortos", que denuncia um intruncado sistema de produção sistemática de mortes como subproduto da formação de clientela prisional, necessária para a credibilidade dos discursos e programas políticos. De outro, por sua vez, os policiais, também, em vulnerabilidade, a mercê de um estado inqusididor e policial.

E é em meio a este duelo que se encontra a sociedade, não como uma vitíma a ser protegida ou uma potencialidade criminosa a ser contida, mas uma produtora e consumidora de estereótipos que ataca e necessita de proteção, que vive e morre em meio a criação e perpetuação polarizante de bem e mal em discursos midiatizados. Em meio a esta fomentação de discursos belicosos de poder, ocasionados pela constante militarização de um lado e criminalização de outro, vê-se a internalização e banalização das formas de violência que 
"fazem parte dessa guerra" de contornos moralizantes.

Neste modelo de sociedade, as violências e as intricandas relações de poder subjugam estes corpos transformando as vidas dos criminalizados em vidas matáveis, reduzindo o impacto das consequências do subproduto criminalizante, e renegando tais mortes ao descaso midiático. Ao tentar compreender esta questão se fez necessário analisar a identidade característica da vida nua no cotidiano prisional brasileiro, bem como a vida precarizada do policial. Um matável por ser criminoso e outro por estar cumprindo seu dever. Essa indiferença com tais mortes são duas faces de uma mesma compreensão vida nua.

Assim, a obra Encuentro (1991) demonstra as distintas formas de poder para além da violência simbólica objetual, sugerindo inúmeras significações dentre elas a mundialização e a exploração do capital e as consequente desigualdade que se relaciona com as demais problematizações. Em meio a este cenário, Duelo (2013) traz a reflexão de combate entre policializados e criminalizados, ambos advindos do mesmo estrato social (vulnerabilizada), que é característico na composição apresentada na obra, pela posição antagônica dos objetos e que são feitos do mesmo material.

Em Insidelout (gun) (1996) que representa, além do objeto que é característico da violência, num jogo de sombras e perspectivas, figuras de distintas de poder. Por "dentro" do objeto acrílico, percebe-se a intenção da autora, indicando as multifacetadas leituras de uma 'arma' (revólver), metaforicamente exteriozado em sujeitos. Por sua vez, a imagem de Crash (2014) remonta em par as consequências de tal duelo e a vida que segue, mesmo com a evidente violência cotidiana. Os simulacros de disparos e tiros produzem uma sensação de medo e apreensão, flertando com a paranoia vivida, principalmente, por aqueles que habitam as grandes cidades.

Pensar em que medida os discursos presentes no campo das artes podem contribuir para discutir as categorias violência e poder no contexto da produção da criminologia cultural e no direito parece ser um ponto de partida, a fim de compreender como o uso de outras linguagens, que não a escrita, enxergam o campo do direito. Importa frisar que a arte sempre terá uma potente característica, a de desvelar os discursos subjacentes. Entende-se que pesquisas que entrelacem os campos das artes visuais e do direito podem ser profícuos espaços investigativos e de reflexão. 


\section{Referências}

AGAMBEN, Giorgio. Homo Sacer: o poder soberano e a vida nua I. Tradução de Henrique Burigo. Belo Horizonte: Editora UFMG, 2002.

BOURRIAUD, Nicolas. Estética relacional. São Paulo: Martins, 2009.

CARVALHO. Salo de. Criminologia Cultural, complexidade e as fronteiras de pesquisa nas ciências criminais. Revista Brasileira de Ciências Criminais, 81. Nov./dez.. IBCCRIM. São Paulo: Revista dos Tribunais, 2009. Disponível em: https://pt.scribd.com/doc/29022481/Carvalho-Salo-Criminologia-Cultural-Complexidade-eas-Fronteiras-de-Pesquisa-nas-Ciencias-Criminais < Acesso em 06/05/2017>.

DIAS, Renato Duro. Interdição de gênero: a lei que silencia o corpo. In: conpedi/ufmg/fumec/ Dom Helder Câmara. (Org.). Direito, arte e literatura. 1ed. Florianópolis: CONPEDI, 2015, v. 1, p. $467-484$.

. Fluxos migratórios e fronteiras: necessárias aproximações entre arte, política e direito.

In: André Karam Trindade; Magno Federici Gomes; Marcelo Campos Galuppo. (Org.). Direito, arte e literatura [Recurso eletrônico on-line] organização CONPEDI/UnB/UCB/IDP/ UDF. 1ed.Florianópolis: CONPEDI, 2016, v. 1, p. 263-283.

FERRELL, Jeff.. Culture, crime, and cultural criminology. Journal of Criminal Justice and Popular Culture, 3(2) (1995) 25-42. Disponível em: http://www.albany.edu/scj/jcjpc/vol3is2/culture.html <acesso 07.05.2017>

FISCHER, Rosa Maria Bueno. O dispositivo pedagógico da mídia: modos de educar na (e pela) TV. Educação e Pesquisa, São Paulo, v.28, n.1, p. 151-162, jan./jun. 2002.

FOUCAULT, Michel. Microfísica do poder. Tradução de Roberto Machado. Rio de Janeiro: Edição Graal, 2009. . Vigiar e punir: nascimento da prisão. Petrópolis, RJ: Vozes, 2014.

GUATARRI, Félix. As três ecologias. Madrid: Pretextos, 1996.

HAAG, Carlos. A mágica das sombras. Entreista com Regina Silveira. Revista Pesquisa FAPESP, 178, dezembro de 2010. p 10-15. Disponível em: http://revistapesquisa.fapesp.br/2010/12/01/regina-silveira-a-m\%C3\%A1gica-das-sombras/ <acesso em 05.05.2017> 
PANOFSKY, Erwin. Iconografia e iconologia: uma introdução ao estudo da arte da renascença. In: Significado nas Artes Visuais. Tradução: Maria Clara F. Kneese e J. Guinsburg. São Paulo: Perspectiva, 2a ed., 1986, p. 47-65.

PANOFSKY, Erwin. Significado nas artes visuais. São Paulo: Perspectiva, 2011.

RODRIGUES, Lígia Luciene. A perspectiva no trabalho de Regina Silveira : uma investigação sobre a utilização da perspectiva na arte contemporânea. Dissertação de Mestrado. Instituto de Artes.. Universidade Estadual de Campinas. Campinas, SP: 2008.

SILVEIRA, Regina. Simulacros. Tese de doutorado em Artes Visuais. Escola de Comunicações e Artes da Universidade de São Paulo sob orientação do Prof. Wolfgang Adolf Arthur Pffeifer. SãoPaulo: Escola de Comunicações e Artes da USP, 1984.

. Compêndio [rs]. Museu de Arte da Pampulha, Belo Horizonte, MG: 2007. 24p.

Disponível em:

http://www.bhfazcultura.pbh.gov.br/sites/bhfazcultura.pbh.gov.br/files/2007 1 CATALOGO \%20REGINA\%20SILVEIRA.pdf 〈acesso em 05.07.2017>

Crash. Catálogo. Curitiba: Museu Oscar Niemeyer, 2015.

- Entrevista com Regina Silveira concedida a Isadora Rupp. Gazeta do Povo.

11.03.2015. Disponível em: http://www.gazetadopovo.com.br/caderno-g/corrupcao-eviolencia-sao-temas-de-exposicao-4melhnxzb1qaw7qk3ekhsiit4 <acesso 05.05.2017>

ZAFFARONI. E. Raúl. A questão criminal. Tradução de Sérgio Lamarão. Rio de Janeiro: Renavan, 2015a.

Em busca das penas perdidas: a perda de legitimidade do sistema penal. Tradução de Vania Romano Pedrosa; Amir Lopes da Conceição. Rio de Janeiro: Renavan, 2015b.

ZAFFARONI. E. Raúl; PIERANGELI, José Henrique. Direito Penal Brasileiro: Primeiro Volume - teoria geral do direito penal. $3^{\text {a }}$. ed. Rio de Janeiro: Revan, 2006. 